OPEN ACCESS

Edited by:

Evelina Leivada,

UiT The Arctic University

of Norway, Norway

Reviewed by:

Natalia Pavlou,

University of Chicago, United States

Sviatlana Vadim Karpava,

University of Central Lancashire,

United Kingdom

*Correspondence:

Stavroula Tsiplakou

stavroula.tsiplakou@ouc.ac.cy

Specialty section:

This article was submitted to

Language Sciences,

a section of the journal

Frontiers in Communication

Received: 01 July 2017 Accepted: 31 October 2017

Published: 20 December 2017

Citation:

Tsiplakou S (2017) Imperfect

Acquisition of a Related Variety?

Residual Clefting and What It Reveals

about (Gradient) Bilectalism.

Front. Commun. 2:17.

doi: 10.3389/fcomm.2017.00017

\section{Imperfect Acquisition of a Related Variety? Residual Clefting and What It Reveals about (Gradient) Bilectalism}

\author{
Stavroula Tsiplakou* \\ Open University of Cyprus, Latsia, Cyprus
}

This article explores the concept of gradient bilectalism by capitalizing on insights from recent developments in second language acquisition, particularly the suggestion that aspects of the syntax-discourse interface that are not easily accessible to the learner may lead to fossilization, even at end state. I explore the implications of this suggestion for bilectal grammars by examining the ways in which speakers of Cypriot Greek do syntactic focusing in Standard Greek. The phenomenon is structurally different in the two varieties of Greek examined: clefting is the Cypriot syntactic focusing strategy par excellence while in Standard Greek the relevant strategy is movement of the focused item to an immediately preverbal position. Interestingly, this focusing strategy is largely unattested in the acrolectal or standard-like production of bilectal Greek Cypriot speakers; on the contrary, the preferred strategy for syntactic focusing appears to be clefting, as is indicated by data from spontaneous speech. Quantitative data from a questionnaire survey presented in this article confirm that such "residual clefting" persists even at end state, which in turn suggests imperfect acquisition of the relevant structural aspect of Standard Greek, the second variety of these otherwise bilectal speakers. The data invite an approach couched within the Interface Hypothesis, and the argument is put forward that, being a structure at the interface between syntax and other modules or cognitive domains (semantics, pragmatics, and discourse), focusing in the target variety is vulnerable as regards acquisition.

Keywords: bilectalism, cleft, clitic, Cypriot Greek, diglossia, focus, interface

\section{INTRODUCTION}

The sociolinguistic situation in the Greek Cypriot speech community arguably still meets the criteria for Fergusonian diglossia, despite ongoing processes of leveling of local subvarieties and the emergence of a pancypriot koine with numerous standard-like structural features (Tsiplakou et al., 2016). The exploration of structural mixing within the Cypriot Greek koine (Tsiplakou, 2014a,b) points to "arrested" convergence to Standard Greek, the H variety in Cyprus's diglossic context. Alternatively put, in terms of acquisition of a second, related variety, it seems that the dialect speaker is not fully bilectal (Grohmann and Leivada, 2012; Rowe and Grohmann, 2013). 
The purpose of this article is to explore what this assumption means for bilectal grammar(s) by looking at syntactic focusing, which is structurally different in the two varieties of Greek in question: clefting is the Cypriot syntactic focusing strategy par excellence; in wh- questions (with the exception of those introduced by $i^{n} d a$ "what") the clefting strategy is optional and arguably conditioned by D-linking (Grohmann et al., 2006; Tsiplakou et al., 2007; Fotiou, 2009; Grohmann, 2009). Interestingly, clefting surfaces consistently in Cypriot speakers' standard-like or acrolectal production, although genuine clefting is unavailable in Standard Greek, with the added wrinkle that in such production the copula inflects for tense and agreement, unlike in the bona fide Cypriot cleft, while the Standard Greek syntactic strategy for focusing, focus movement, is largely unattested in the acrolectal production of bilectal speakers (Tsiplakou, 2014a). Such "residual clefting" data arguably invite an approach whereby an aspect of the syntax of the target variety which relates to the syntax-discourse interface has strong effects on syntactic acquisition (Sorace, 2011; Tsiplakou, 2014a).

\section{BILECTALISM IN CYPRUS: STRUCTURAL AND SOCIOLINGUISTIC FACTORS}

Unlike other geographical Greek varieties, which have been leveled out or are undergoing sweeping processes of leveling (Contosopoulos, 1969), and despite the fact that diglossia between Cypriot and Standard Greek is still going strong (Papapavlou, 1998; Arvaniti, 2010; Hadjioannou et al., 2011; Tsiplakou, 2011; Rowe and Grohmann, 2013), Cypriot Greek is a variety that still by-and-large resists full dedialectalization (Tsiplakou, 2011, 2014a,b; Rowe and Grohmann, 2013). ${ }^{1}$ As has been argued in previous work, dense contact between Standard and Cypriot Greek as well as a host of historical, socio-political, economic, and demographic factors have spurred on currently ongoing processes of leveling of local varieties and the emergence of a pancypriot koine (Terkourafi, 2005; Tsiplakou, 2006, 2009a,b; Tsiplakou et al., 2006, 2016; Tsiplakou and Kontogiorgi, 2016), which now stands in a diglossic relationship to Standard Modern Greek. The koine acts as a robust buffer against dedialectalization in virtue of the fact that it is (perceived as) a hybrid system, displaying strong structural influences from Standard Modern Greek; such standard-like structural aspects allow for what Rowe and Grohmann (2013) have aptly termed (co-)overt prestige to accrue to the koine, due to is perceived, if not actual, convergence with the standard variety (Tsiplakou, 2011, 2014b).

Such structural quasi-convergence with Standard Greek results in hybrid structural patterns akin to code mixing, which are however pragmatically/discursively difficult to interpretas codemixing since they seem to serve no obvious discourse purpose, suggesting instead that some kind of grammatical convergence is at work. ${ }^{2}$

${ }^{1}$ Dedialectalization is defined as full leveling of a variety and its subvarieties and concomitant convergence to a related standard (see, e.g., Trudgill, 1999; Kerswill, 2010). The data presented in this paper provide further evidence against the full dedialectalization of Cypriot Greek.

${ }^{2}$ Hence the argument for the availability for competing grammars (Kroch, 1994; Kroch and Taylor, 2000) put forward in Tsiplakou (2009a,b, 2014a) and taken up in Grohmann et al. (2017).
In previous work I have suggested that such structural hybridity ultimately "does not allow the two systems to merge fully, as convergence qua structural mixing is mostly achieved through (surface) morphological, as well as lexical, choices, while Cypriot phonology and syntax remain largely intact" (Tsiplakou, 2014b: 164). The argument was based on the availability in acrolectal/ standard-like registers of the koine of structures where surface lexical or morphological exponents from Standard Greek are inserted in structures which are otherwise bona fide Cypriot (or common to both varieties), giving the data its hybrid, quasistandard flavor, as in (1), where the accusative plural of the feminine determiner appears in the same utterance in both its Standard Greek and its Cypriot form (tis and tes, respectively) ${ }^{3}$ :

\begin{tabular}{llll}
\hline (1) na & $\begin{array}{l}\text { endopísume }^{\text {sot.PERF.1P }} \\
\text { spot }\end{array}$ & $\begin{array}{l}\text { tis } \\
\text { the ACC.FEM.P }\end{array}$ & $\begin{array}{l}\text { ðinatótites } \\
\text { strength.ACC.FEM.P }\end{array}$ \\
ce & tes & aðinamíes & \\
and & the.ACC.FEM.P & weakness.ACC.FEM.P & \\
\hline
\end{tabular}

"in order to spot the strengths and the weaknesses"

In (1) above, the underlying syntactic structure and the morphosyntactic features of the determiner are identical in both varieties; of much greater interest are cases of hybrid production where the syntactic properties of the two varieties differ. Syntactic focusing is a very interesting case in point, not least because, together with clitic placement, it is one of the two core syntactic areas distinguishing the two varieties in question.

\section{CLEFTS IN THE CYPRIOT KOINE AND IN STANDARD(-LIKE) PRODUCTION}

Cypriot Greek has focus clefts (Grohmann et al., 2006; Tsiplakou et al., 2007; Grohmann, 2009) whereas in Standard Greek syntactic focusing involves movement of the focused element to a position in the left periphery (a syntactic Focus Phrase above TP) and verb raising (Tsimpli, 1995, 1998):

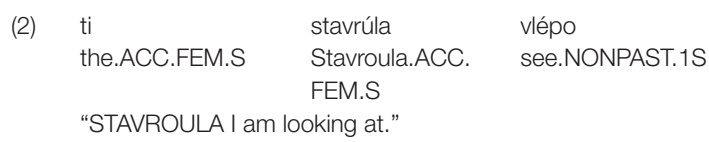

(Standard Greek)

${ }^{3}$ The converse pattern obtains in the innovative periphrastic tenses of Cypriot Greek, where dialectal phonology and syntax (e.g., clitic-second effects) occur in innovative, morphologically and semantically standard-like, periphrastic perfect tense structures (Tsiplakou et al., 2016):

\begin{tabular}{|c|c|c|c|c|c|c|c|}
\hline $\begin{array}{l}\text { íxamen } \\
\text { had.1P }\end{array}$ & \multicolumn{2}{|c|}{$\begin{array}{l}\text { t } \text { tin } \\
\text { that.ACC.MASC.S }\end{array}$} & \multicolumn{2}{|c|}{$\begin{array}{l}\text { ton } \\
\text { the ACC.MASC.S }\end{array}$} & \multicolumn{3}{|c|}{$\begin{array}{l}\text { filóloyon } \\
\text { Greek teacher.ACC.MASC.S }\end{array}$} \\
\hline $\begin{array}{l}\text { on } \\
\text { he.MASC }\end{array}$ & .ACC.S & $\begin{array}{l}\text { fasísta } \\
\text { fascist. }\end{array}$ & MASC.ACO & & & & \\
\hline lad.3S & $\begin{array}{l}\text { mas } \\
\text { us.CL.GEN }\end{array}$ & $\begin{array}{l}\text { ta } \\
\text { ther }\end{array}$ & 7.CL.ACC & $\begin{array}{l}\text { príksi } \\
\text { swollen }\end{array}$ & $\begin{array}{l}\text { me } \\
\text { with }\end{array}$ & $\begin{array}{l}\text { tin } \\
\text { the.ACC. } \\
\text { FEM.S }\end{array}$ & $\begin{array}{l}\text { eóka } \\
\text { EOKA }\end{array}$ \\
\hline
\end{tabular}

"We had this Greek teacher, a total fascist; he had busted us our balls about EOKA." (Melissaropoulou et al., 2013; Tsiplakou et al., 2016). 


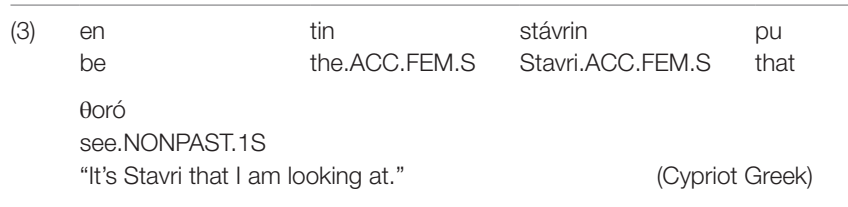

Cypriot Greek presents an added wrinkle: there is a Cypriotspecific clefting strategy (of the est-ce que type) available in wh- questions; it is obligatory in wh- questions introduced by $i^{n} d a$ "what" when $i^{n} d a$ is an argument and it is optional when $i^{n} d a$ is adverbial. In the case of all other wh- expressions, the clefting strategy is optional and arguably associated with a D-linked interpretation for the wh- expression that is "doubled" by en pu "is that" (the Cypriot equivalent of est-ce que, $m$ bu below being its phonetically reduced form; see Grohmann et al., 2006; Tsiplakou et al., 2007; Grohmann, 2009; Kanikli, 2011):

\begin{tabular}{|c|c|c|c|c|c|}
\hline \multirow[t]{4}{*}{ (4) } & a. & $\begin{array}{l}\text { inda } \\
\text { what.ACC }\end{array}$ & $\begin{array}{l}\mathrm{m} \\
\text { be }\end{array}$ & $\begin{array}{l}\text { bu } \\
\text { that }\end{array}$ & $\begin{array}{l}\text { kámni } \\
\text { do. } \\
\text { NONPAST.3S }\end{array}$ \\
\hline & & $\begin{array}{l}\text { i } \\
\text { the.FEM.NOM.S } \\
\text { "What is it that Stavri i }\end{array}$ & is doing?" & & $\begin{array}{l}\text { stávri } \\
\text { Stavri. } \\
\text { FEM.NOM.S }\end{array}$ \\
\hline & b. & $\begin{array}{l}{ }_{\text {wnda }} \\
\text { what.ACC } \\
\text { "What is it that Stavri i }\end{array}$ & $\begin{array}{l}\text { kámni } \\
\text { do. } \\
\text { NONPAST.3S } \\
\text { is doing?" }\end{array}$ & $\begin{array}{l}\text { i } \\
\text { the. } \\
\text { FEM.NOM.S }\end{array}$ & $\begin{array}{l}\text { stávri? } \\
\text { Stavri. } \\
\text { FEM.NOM.S }\end{array}$ \\
\hline & c. & $\begin{array}{l}\text { pcos } \\
\text { who.MASC.NOM.S } \\
\text { "Who \{is it that\} came }\end{array}$ & $\begin{array}{l}\text { \{en } \\
\text { \{be } \\
\text { ?" }\end{array}$ & $\begin{array}{l}\text { pu\} } \\
\text { that\} }\end{array}$ & $\begin{array}{l}\text { írten? } \\
\text { come.PAST.3S }\end{array}$ \\
\hline
\end{tabular}

By contrast, Standard Greek exhibits only wh- movement, the feature $[w h]$ inducing verb raising to $\mathrm{C}$ :

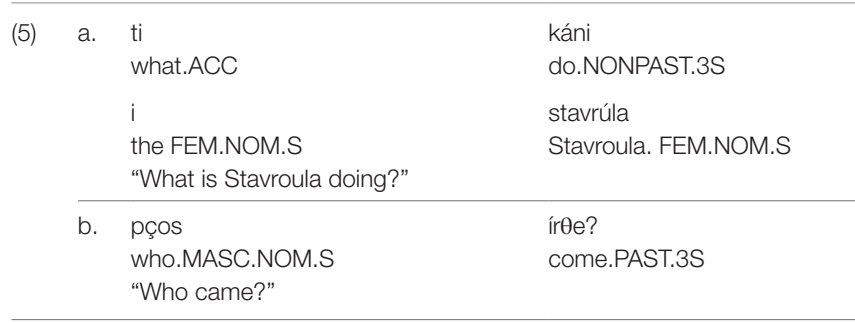

In previous work (Tsiplakou, 2009a,b, 2014a,b), data from spontaneous speech production in Cypriot Greek were discussed in which Cypriot focus and wh-clefts display some rather unexpected surface properties: there are instances of focus clefts with the Standard Greek third person copula ine, rather than the Cypriot en [a form which looks like the third person singular or plural form of the copula but which in fact lacks tense or agreement features, as has been argued in Grohmann et al. (2006) and Tsiplakou et al. (2007); see Merchant and Pavlou (2017) for further extensive discussion]:

\begin{tabular}{lllll}
\hline (6) íne $\quad$ fitités & pu & 日a & aksiolojísume \\
be student.MASC.ACC.P & that & FUT & evaluate.1P \\
& "It's students that we will evaluate." & & & \\
\end{tabular}

There are also some occurrences of focus clefts cum focus movement to the left of the "copula" (see also Gryllia and Lekakou, 2007; Fotiou, 2009; Papadopoulou et al., 2014):

\begin{tabular}{|c|c|c|c|c|c|}
\hline \multirow[t]{5}{*}{ (7) } & $\begin{array}{l}\text { teliká } \\
\text { ultimately }\end{array}$ & $\begin{array}{l}\text { o } \\
\text { the.MASC. } \\
\text { NOM.S }\end{array}$ & $\begin{array}{l}\text { arçiepískopos } \\
\text { archbishop. } \\
\text { MASC.NOM.S }\end{array}$ & $\begin{array}{l}\text { íne } \\
\text { be }\end{array}$ & $\begin{array}{l}\mathrm{pu} \\
\text { that }\end{array}$ \\
\hline & ta & ðiicí & óla & & \\
\hline & CL.NEUT. & rule. & all.NEUT. & & \\
\hline & ACC.P & NONPAST.3S & ACC.P & & \\
\hline & \multicolumn{5}{|c|}{ "Ultimately, it's the Archbishop that rules everything." } \\
\hline \multirow[t]{6}{*}{ (8) } & pcos & én:a & me & katanfili? & \\
\hline & who.MASC. & FUT & me.CL.MASC. & denounce.3S & \\
\hline & stin & cípron & en & $\mathrm{pu}$ & ímasten \\
\hline & in the.FEM. & Cyprus.ACC & be & that & \\
\hline & ACC.S & & & & NONPAST.1P \\
\hline & "Who is going & . & 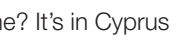 & tho & \\
\hline
\end{tabular}

The standard-like form of the "copula" may furthermore inflect for tense, although, at least in the data from spontaneous production, there are no instances of the copula inflecting for agreement; the Cypriot-specific est-ce que type strategy may also occur in wh-questions with the standard form of the copula (also inflecting for tense but arguably not for agreement):

\begin{tabular}{|c|c|c|c|c|}
\hline (9) & $\begin{array}{l}\text { ítan } \\
\text { be.PAST } \\
\text { "It was am }\end{array}$ & $\begin{array}{l}\text { metaksí tus } \\
\text { among them } \\
\text { mselves that th }\end{array}$ & $\begin{array}{l}\text { pu } \\
\text { that } \\
\text { having fun." }\end{array}$ & $\begin{array}{l}\text { eðiaskeðázan } \\
\text { have fun.PAST.3P }\end{array}$ \\
\hline (10) & $\begin{array}{l}\text { pu } \\
\text { where } \\
\text { "Where wa }\end{array}$ & $\begin{array}{l}\text { ítan } \\
\text { be.PAST } \\
\text { t she spoke?" }\end{array}$ & $\begin{array}{l}\mathrm{pu} \\
\text { that }\end{array}$ & $\begin{array}{l}\text { emílisen? } \\
\text { speak.PAST.3S }\end{array}$ \\
\hline
\end{tabular}

Of particular interest for this discussion is the fact that clefts also show up in written production by Cypriot Greek speakers, in texts otherwise written in Standard Greek, e.g., in the newspaper articles in (11) and (12) below ${ }^{4}$ :

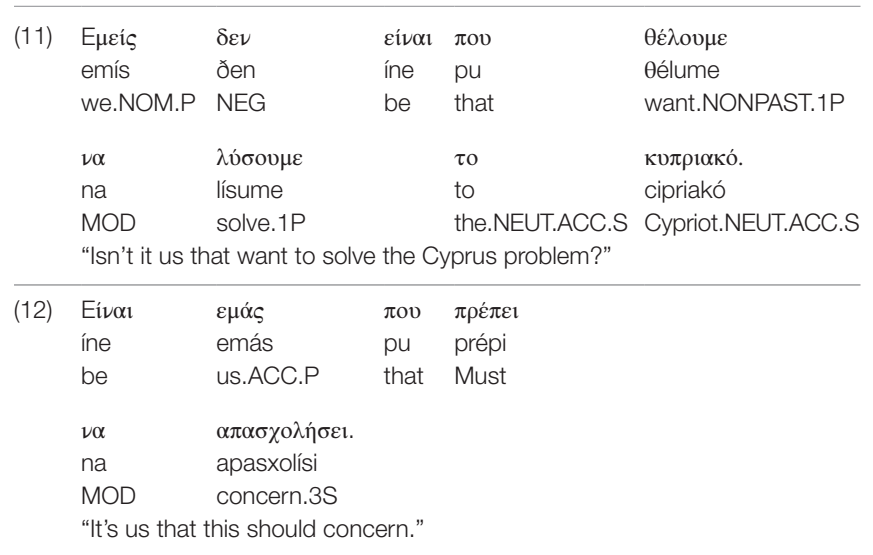

${ }^{4}$ Sources: http://politis.com.cy/article/o-nikos-pou-xeperase-ton-tasso and http://

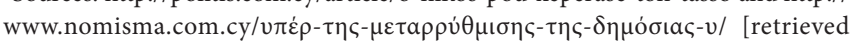
07/18/2017]. 
In earlier work, it was suggested that "such cases may be treated as arising as a result of an extension of a grammatical structure of the base variety in an attempt to fit the 'perceived' structural properties of the target variety" as "the structural properties of the target variety may not be fully recoverable" (Tsiplakou, 2014b: 175; cf. Tsiplakou, 2014a), an issue which will be taken up in detail in this article.

\section{QUANTITATIVE DATA}

\section{Convergence to Standard Greek Does Not Affect Clefting}

The data presented above were sampled from spontaneous speech (Tsiplakou, 2014a,b; Tsiplakou et al., 2016). In this section, I will present quantitative data from a questionnaire survey, which indicate that clefting displays resistance to language shift; I will attempt to relate the resilience of focus clefting to acquisition factors, with the hope of shedding some (more) light on the notion of gradient bilectalism.

In Tsiplakou et al. (2016), a sociolinguistic study is presented the aim of which was to gage whether there is consistency and coherence vis-à-vis rates of occurrence of particular variants, either Cypriot or standard(-like). The methodology adopted was the sociolinguistic interview; the two interviewers, both young males, were speakers of Cypriot Greek, who used the koine throughout, taking care to speak relatively informally. Participants were asked to relate something exciting or emotionally loaded (typically a previous experience) to ensure spontaneity and naturalness in their linguistic production. A total of 57 participants were interviewed, 29 males and 28 females. Their ages ranged from 26 to 90 . The participants' profiles were similar in all respects except age, gender and education. All were city dwellers. The variants analyzed quantitatively were (i) the ratio of [f] over [ç], (ii) the ratio of [ $\mathrm{t}]$ ] over [c], (iii) the ratio of Simple Past over the innovative periphrastic tenses and (iv) the ratio of enclisis over (unexpected) proclisis. ${ }^{5}$ The finding which is of relevance for the discussion in this article is the fact that in that sample there was not a single instance of the Standard Greek syntactic focusing strategy, focus raising; by contrast, every single instance of syntactic focusing involved clefting. This finding is in stark contrast to the variation exhibited in the phonological data and the data involving periphrastic tenses and clitic placement. In all of these areas, standard-like variants were ubiquitously present in the participants' oral production. ${ }^{6}$

${ }^{5}$ As regards the correlations among these variants and their correlation with extralinguistic factors, the reader is referred to Tsiplakou et al. (2016) for extensive discussion.

${ }^{6}$ Below are examples of "unexpected" proclisis or exceptional clitic placement, i.e., proclisis without a triggering element in the $\mathrm{C}$ field:

\begin{tabular}{|c|c|c|}
\hline a. kséro & to & túto \\
\hline know.NONPAST.1S & it.NEUT.ACC.S & this.NEUT.ACC.S \\
\hline $\begin{array}{l}\text { kséro } \\
\text { know.NONPAST.1S }\end{array}$ & $\begin{array}{l}\text { to } \\
\text { it.NEUT.ACC.S }\end{array}$ & \\
\hline
\end{tabular}

Of special interest here is the syntactic variation in the data from the other core syntactic area where Cypriot differs radically from Standard Greek, namely pronominal clitic placement. As is well-known, the generalization is that in Standard Greek proclisis (clitic placement in the immediately preverbal position) depends on the finiteness of the verb form, hence gerunds and imperatives trigger enclisis; Cypriot Greek displays clitic-second/ Wackernagel or, alternatively, Tobler-Mussafia effects (Horrocks, 1990; Terzi, 1999; Agouraki, 2001; Condoravdi and Kiparsky, 2002; Pappas, 2004, 2014; Revithiadou, 2006, 2008; Tsiplakou, 2006; Chatzikyriakidis, 2010, 2012; Mavrogiorgos, 2010, 2013; Grohmann, 2011; Neokleous, 2015; Grohmann et al., 2017 among others). As with the other variants, while the Cypriot structure, enclisis, was the preferred option, the standard-like strategy of proclisis without a triggering element in $\mathrm{C}$ or below, i.e., exceptional clitic placement, was certainly present in that extensive sample of Cypriot Greek oral production. ${ }^{7}$ It would then seem that proclisis is seeping into Cypriot Greek grammar (or that competing grammars are at work). This is, however, clearly not the case with focus raising; by contrast, the Cypriot syntactic focusing strategy appears to be used in lieu of focus raising even in production which is (or attempts to be) standard-like [as is also indicated by examples such as (7), (11), and (12) above].

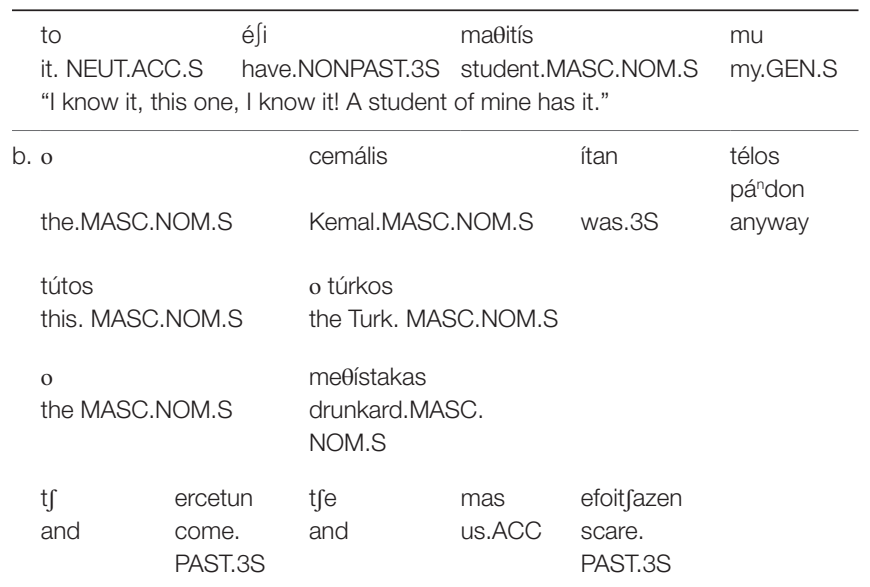

"Anyway, Kemal was this Turkish drunkard, and he would come and scare us."

\begin{tabular}{|c|c|c|c|}
\hline \multirow{2}{*}{\multicolumn{4}{|c|}{$\begin{array}{ll}\text { pas:á } & \text { ðen } \\
\text { in the past } & \text { NEG }\end{array}$}} \\
\hline & & & \\
\hline \multicolumn{2}{|l|}{ tin } & cipriací & ðiálekto \\
\hline \multicolumn{2}{|c|}{ the.FEM.ACC.S } & Cypriot.FEM.ACC.S & dialect.FEM.ACC.S \\
\hline \multicolumn{2}{|l|}{ tin } & e日eórun & đíyman \\
\hline \multicolumn{2}{|c|}{ CL.FEM.ACC.S } & consider.PAST.1S & sign.NEUT.ACC.S \\
\hline \multicolumn{4}{|l|}{ amorfojás } \\
\hline \multicolumn{4}{|c|}{ illiteracy.FEM.GEN.S } \\
\hline
\end{tabular}

Such exceptional clitic placement occurred at 19\% in the data in Tsiplakou et al., 2016.

${ }^{7}$ Leivada et al. (2017) present comparable data, with exceptional clitic placement reaching $17 \%$ in their spontaneous speech corpus (which however contained data from five participants). On the whole, both studies present data that may plausibly be taken to attest to the partial reshuffling of the syntax of cliticization in Cypriot Greek. 


\section{The Study}

As the numerical data from the study in Tsiplakou et al. (2016) were too few to make meaningful comparisons, and, crucially, as it is impossible to draw any conclusions based solely on the absence of a phenomenon in a particular sample, indicative though that absence may be, for the purposes of this article a questionnaire survey was conducted, the focus of which was to gage whether this absence relates to the observation made in previous work and already discussed above to the effect that Cypriot Greek speakers opt for clefting rather than focus movement even in acrolectal/ standard-like production, moreover couching the clefted structure in Standard Greek phonology and morphology. The case can then be made that Cypriot Greek speakers treat clefts as part of the grammar of the standard variety, while Standard Greek focus movement slips under the radar, as it were. If this is the case, the findings can be taken to suggest a transfer effect from Cypriot Greek in the acquisition of the standard variety, which needs to be accounted for (cf. Tsiplakou, 2014a,b). ${ }^{8}$

\section{The Questionnaire}

The questionnaire, which was administered electronically, tested for the acceptability of Cypriot-like focus clefts of the following types: (a) clefted adverbials/PPs (two items), (b) clefted first and second person pronominal subjects (four items), (c) clefted third person subjects, pronominal and non-pronominal (two items), (d) clefted direct objects, pronominal and non-pronominal (six items), (e) clefted indirect object PPs (P + ACC, two items) and (f) clefted indirect objects in genitive (two items). The questionnaire also contained nine fillers. Examples of questionnaire items are provided below:

${ }^{8}$ The study was carried out in accordance with the general recommendations of the Cyprus National Bioethics Committee and with written, informed consent from the subjects; ethics approval was not required as per the Open University of Cyprus guidelines and national regulations.

\begin{tabular}{|c|c|c|c|c|c|c|}
\hline \multirow[t]{7}{*}{ (13) } & 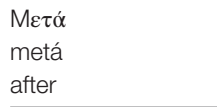 & $\begin{array}{l}\alpha \pi \text { ó } \\
\text { apó } \\
\text { from }\end{array}$ & $\begin{array}{l}\pi 0 \lambda \lambda \varepsilon ́ \varsigma \\
\text { polés } \\
\text { many.FEM.ACC.P }\end{array}$ & & 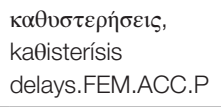 & \\
\hline & 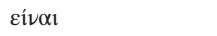 & 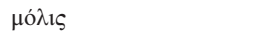 & $\chi \tau \varepsilon \varsigma$ & $\pi \mathrm{ov}$ & $\alpha \rho \rho \chi 1 \sigma \alpha \nu$ & \\
\hline & íne & mólis & xtes & $\mathrm{pu}$ & árçisan & \\
\hline & be & just & yesterday & that & start.PAST.3S & \\
\hline & $\pi \alpha ́ \lambda_{1}$ & $\mathrm{ol}$ & & 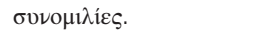 & & \\
\hline & páli & & & sinomilíes & & \\
\hline & again & the.FEM.NOM.P & & talks.FEM.NOM.P & & \\
\hline \multirow[t]{13}{*}{ (14) } & Пó $\lambda_{1}$ & $\varphi \alpha \sigma \alpha \rho i ́ \varepsilon \varsigma$ & & $\dot{\varepsilon} \chi о v \mu \varepsilon$ & & \\
\hline & páli & fasaríes & & éxume & & \\
\hline & again & troubles. FEM.NOM.P & & have.NONPAST.1P & & \\
\hline & $\sigma \tau \eta$ & & 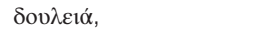 & & & \\
\hline & & & ðuКá & & & \\
\hline & at the.FEM.ACC.P & & & work. FEM.ACC.P & & \\
\hline & $\kappa \alpha_{1}$ & cívol & $\varepsilon \gamma \omega \dot{0}$ & $\pi \mathrm{ov}$ & $\theta \alpha$ & $\tau \alpha$ \\
\hline & $\mathrm{ce}$ & íne & eyó & $\mathrm{pu}$ & $\theta a$ & ta \\
\hline & and & be & I.NOM.S & that & FUT & them.CL.ACC.P \\
\hline & $\tau \rho \alpha \beta \dot{\eta} \xi \omega$ & & ó $\lambda \alpha$. & & & \\
\hline & travíkso & & óla & & & \\
\hline & suffer.1S & & all.NEUT.ACC.P & & & \\
\hline & "We have problems & 'ork again, and it's I that' & unt of if all." & & & \\
\hline \multirow[t]{13}{*}{ (15) } & ${ }^{\prime} \mathrm{E} \chi \omega$ & $\pi \circ \lambda \lambda \circ \operatorname{ov́}_{\varsigma}$ & 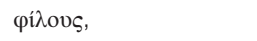 & & & \\
\hline & éxo & polús & fílus & & & \\
\hline & have.NONPAST.1S & many.MASC.ACC.P & friends.MASC.ACC.P & & & \\
\hline & $\alpha \lambda \lambda \alpha{ }^{\prime}$ & cívol & o & $\Sigma \pi u ́ \rho \circ \varsigma$ & $\pi \circ 0$ & \\
\hline & alá & íne & o & spíros & pu & \\
\hline & but & be & the.MASC.NOM.S & Spyros.MASC.NOM.S & that & \\
\hline & $\mu \varepsilon$ & & $\sigma \tau \eta \rho i \zeta \varepsilon \varepsilon$ & & & \\
\hline & me & & stirízi & & & \\
\hline & me.CL.ACC.S & & support.NONPAST.3S & & & \\
\hline & $\sigma \tau \alpha$ & & $\delta \hat{\sigma} \sigma \kappa о \lambda \alpha$. & & & \\
\hline & sta & & ðískola & & & \\
\hline & in the.NEUT.ACC.P & & difficulty.NEUT.ACC.P & & & \\
\hline & "I have many friends & t it's Spyros who stands & the going gets tough." & & & \\
\hline \multirow[t]{3}{*}{ (16) } & $\Sigma \tau \eta \nu$ & $\pi \alpha \rho \circ v ́ \sigma \alpha$ & $\pi \mathrm{o} \lambda ı \imath ı \kappa \eta ́$ & & & \\
\hline & stin & parúsa & politicí & & & \\
\hline & in the.FEM.ACC.S & current.FEM.ACC.S & political.FEM.ACC.S & & & \\
\hline
\end{tabular}




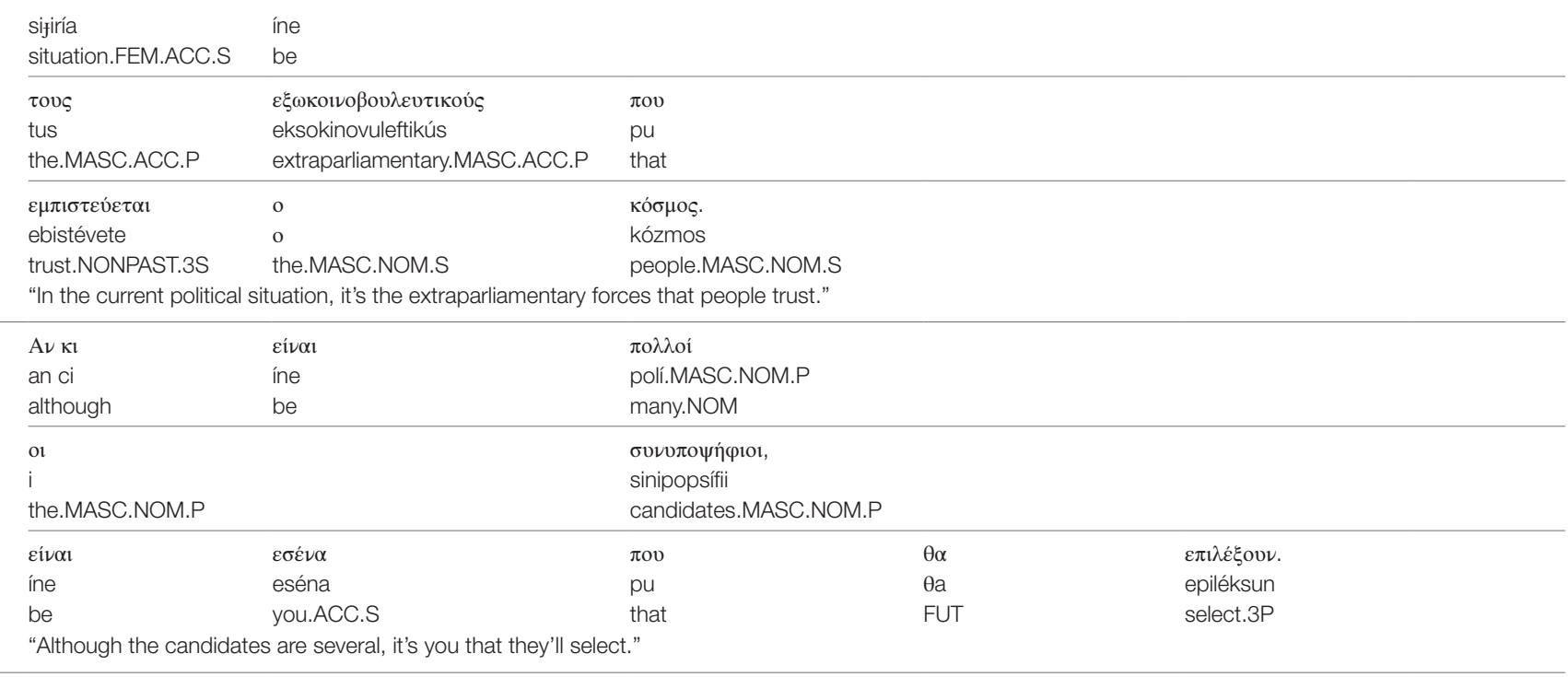

The 12 controls, all highly educated monolingual speakers of Standard Greek, all found the questionnaire items ungrammatical. ${ }^{9}$

Participants were asked to rate the sentences as grammatical or ungrammatical in Standard Greek and were moreover asked to suggest corrections in case they thought the sentences were ungrammatical. Data were discarded in case the corrections were irrelevant to the focus of the study. ${ }^{10}$

${ }^{9}$ The controls were also asked to correct the sentences; all opted for focus movement, as in

\begin{tabular}{lll}
\hline Eó́v $\alpha$ & $\theta \alpha$ & $\varepsilon \pi \lambda \dot{\varepsilon} \xi$ ovv. \\
eséna & $\theta a$ & epiléksun \\
you.ACC.S & FUT & select.3P \\
\hline
\end{tabular}

A second choice for some of the controls was a structure involving an inflected copula and a relative clause, which has only partial similarity to the Cypriot cleft, e.g.:

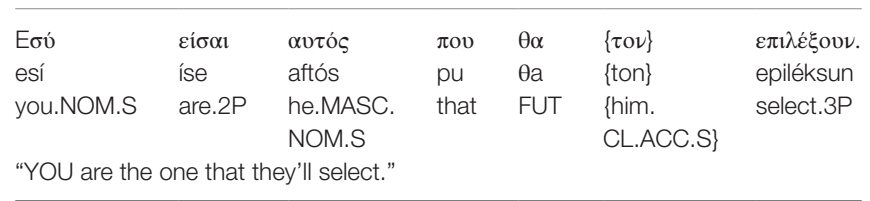

This structure, however, differs from the Cypriot cleft in several important respects: first, it involves an inflected copula and number and person agreement between the copula and the focused item, which, crucially, has been changed to a subject; second, the nominative case on the focused element along with the presence of an object pronoun in the relative clause suggests that no extraction of the focused object out of the non-matrix clause has taken place; this is a major difference to true focus clefts such as the Cypriot Greek ones, where the focused element in the cleft retains what case marking corresponds to its position within the lower clause (e.g., accusative for the direct object in the example above) and the use of a resumptive pronoun results in ungrammaticality.

${ }^{10}$ The questionnaire also examined the acceptability of focus clefts cum focus movement to the left of the "copula"; the results for these items will be discussed in future work.

\section{Participants}

A total of 96 subjects participated in the study, 61 females and 35 males. All identified themselves as native speakers of Cypriot Greek. All participants were born and raised in Cyprus, they had Greek Cypriot parents, and there were no bilingual speakers in the sample. Their ages ranged from 18 to $70(\mathrm{M}=37.1$, $\mathrm{SD}=11.1)$. As regards age groups, 64 were younger than 40 , while the rest (32) were 40 years old or older. It is worth noting that most participants were quite highly educated (with degrees from tertiary education or higher at $92 \%$ ), while the rest ( $8 \%$ ) had only completed secondary education. The high education level of participants may in fact be advantage, if not a desideratum, in this case as highly educated speakers can be reasonably assumed to be highly proficient speakers of Standard Greek, so their judgments reflect accurately the acquisition of the phenomenon in question at end state.

Regarding geographical provenance, 60 participants were of urban origin, while 36 were of rural origin $;{ }^{11}$ the expectation was that the urban-rural distinction would be more relevant than precise geographical provenance for the purposes of this discussion.

\section{RESULTS}

Overall, participants accept clefting as a focusing strategy in Standard Greek at 53\%. A binomial test indicated that the

${ }^{11}$ Participant groupings into areas of origin are shown in the following table:

\begin{tabular}{lrr}
\hline & $M$ & $N$ \\
\hline Lefkosia & $47 \%$ & 45 \\
Lemesos & $20 \%$ & 19 \\
Larnaka & $13 \%$ & 12 \\
Ammochostos & $11 \%$ & 11 \\
Pafos & $9 \%$ & 9
\end{tabular}

Grouping of subjects according to area of origin. 
observed acceptance rate of clefts (53\%) was significantly different from the $50 \%$ chance level, $p=0.017$ (two-sided). ${ }^{12}$

A logistic regression was performed to ascertain the effects of gender, age group, education, area of origin and the urbanrural distinction on the likelihood that participants accept cleft structures in otherwise Standard Greek sentences (see Table 1). The logistic regression model was statistically significant, $\chi^{2}(23)=217.096, p<0.0005$. The model explained $16.4 \%$ (Nagelkerke $R^{2}$ ) of the variance in cleft acceptability and correctly classified $62.8 \%$ of cases.

${ }^{12}$ I am very grateful to Spyros Armostis for his invaluable help with the analysis.

TABLE 1 | Logistic regression results.

\begin{tabular}{|c|c|c|c|c|c|}
\hline & \multirow[t]{2}{*}{$b$ (SE) } & \multirow[t]{2}{*}{ Sign. } & \multirow[t]{2}{*}{$\operatorname{Exp} b$} & \multicolumn{2}{|c|}{$\begin{array}{c}95 \% \mathrm{Cl} \text { for } \\
\quad \operatorname{exp~} b\end{array}$} \\
\hline & & & & Lower & Upper \\
\hline \multicolumn{6}{|l|}{ Included } \\
\hline Gender & $0.913(0.302)$ & 0.002 & 2.491 & 1.379 & 4.500 \\
\hline Age group & $2.637(0.878)$ & 0.003 & 13.969 & 2.500 & 78.046 \\
\hline Area (Lemesos) & $-2.405(0.498)$ & $<0.0005$ & 0.090 & 0.034 & 0.239 \\
\hline Area (Pafos) & $-4.408(1.241)$ & $<0.0005$ & 0.012 & 0.001 & 0.139 \\
\hline
\end{tabular}

$R^{2}=0.095$ (Hosmer and Lemeshow), 0.123 (Cox and Snell), 0.164 (Nagelkerke). Model $\chi^{2}(23)=217.096, p<0.0005$. Percentage of correct prediction: $62.8 \%$.
As can be seen from Figure 1, males accepted clefts were 2.491 times that of females, $b=0.913$, Wald $\chi^{2}(1)=9.144, p=0.002$. Males $(M=57 \%)$ accepted clefts at higher rates compared with females $(\mathrm{M}=51 \%)$.

The odds of older subjects $(\geq 40)$ accepting clefts was 13.969 times that of younger subjects $(<40), b=0.913, \mathrm{~W} b=2.637$, Wald $\chi^{2}(1)=9.023, p=0.003$. As can be seen from Figure 2 , older subjects $(M=56 \%)$ accepted clefts at higher rates compared with younger subjects $(M=51 \%)$.

Quite interestingly, there was no statistically significant difference between subjects of tertiary and secondary education (Figure 3).

Also quite interestingly, there was no statistically significant difference between subjects of urban and rural origin (Figure 4). ${ }^{13}$

The data were further analyzed on the basis of cleft type. Results were as follows (Figure 5):

A binomial test indicated that the observed acceptance rate of Clefted Adverbials/PPS (41\%) was significantly different from the $50 \%$ chance level, $p=0.014$ (two-sided).

A binomial test indicated that the observed acceptance rate of Clefted Subjects (third person) (68\%) was significantly different from the $50 \%$ chance level, $p<0.0005$ (two-sided).

${ }^{13} \mathrm{As}$ regards precise area of origin, overall this was not a predictive factor, as expected.

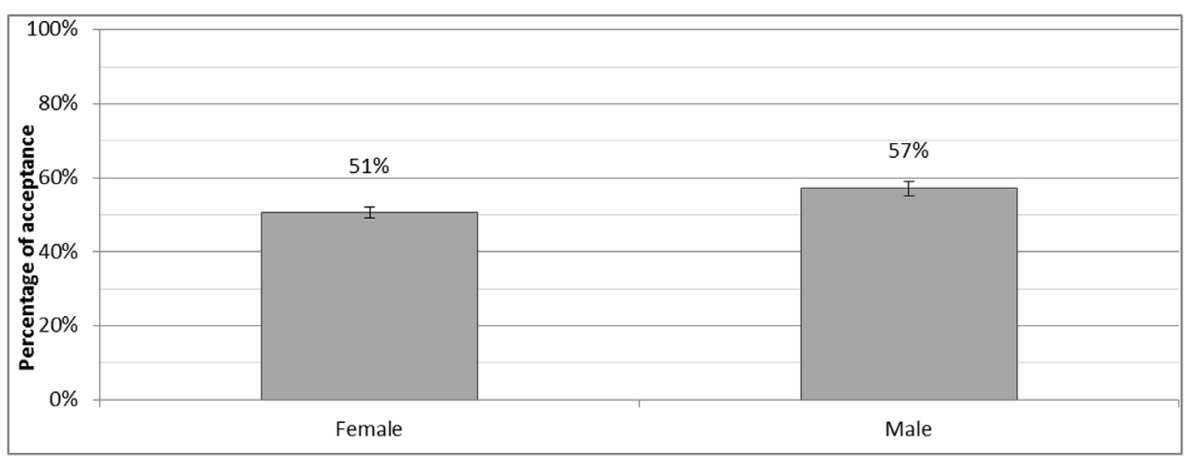

FIGURE 1 | Rates of cleft acceptance as a function of gender.

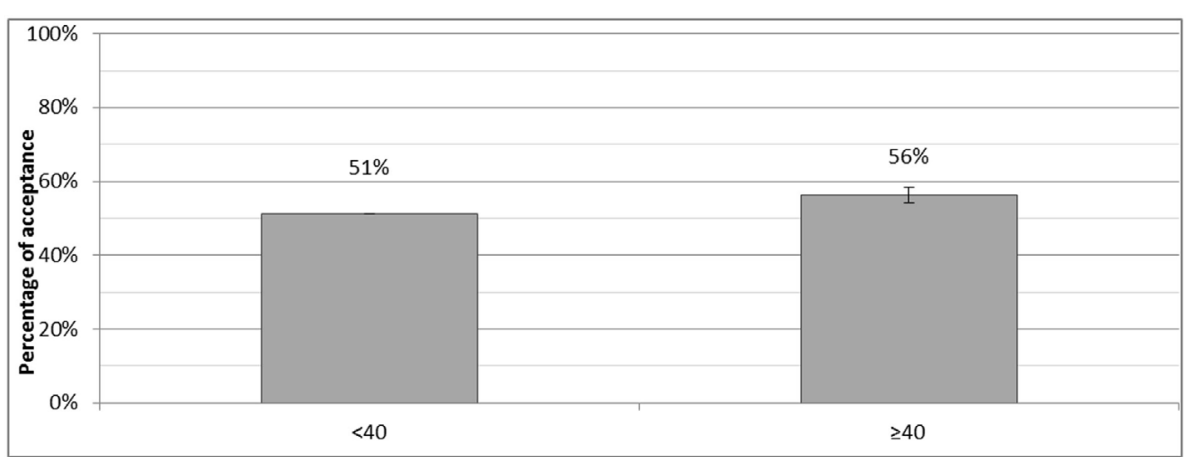

FIGURE 2 | Rates of cleft acceptance as a function of age group. 


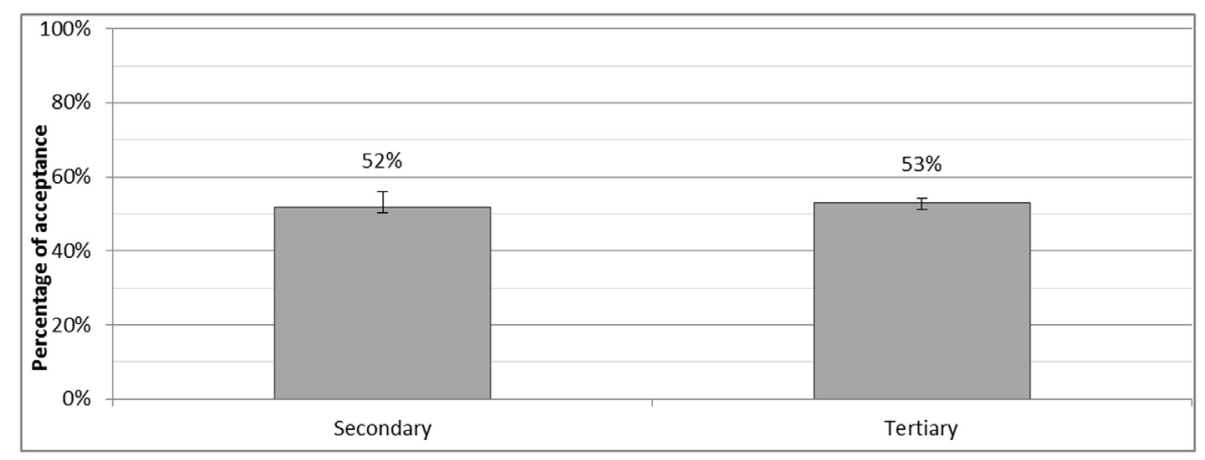

FIGURE 3 | Rates of cleft acceptance as a function of education.

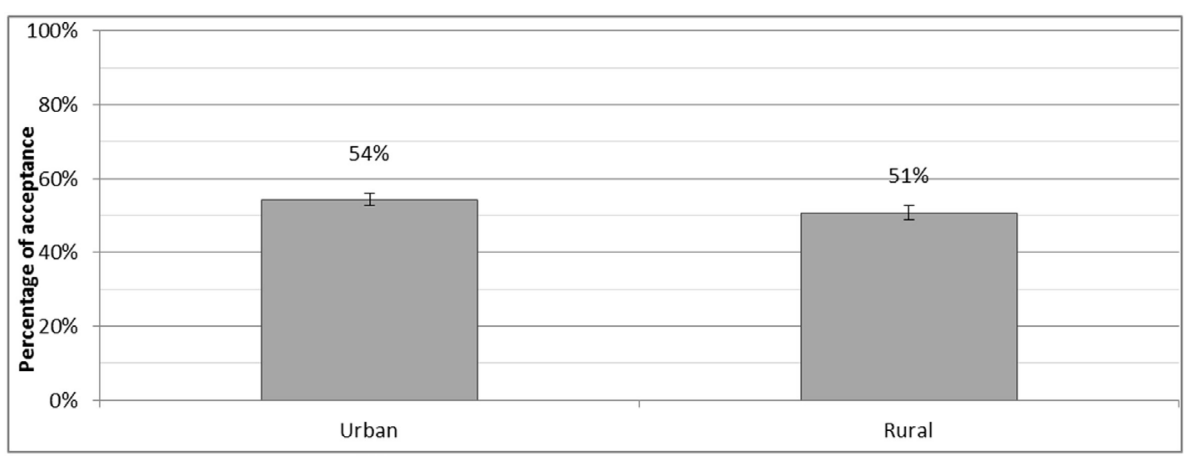

FIGURE 4 | Rates of cleft acceptance as a function of urban vs rural provenance.

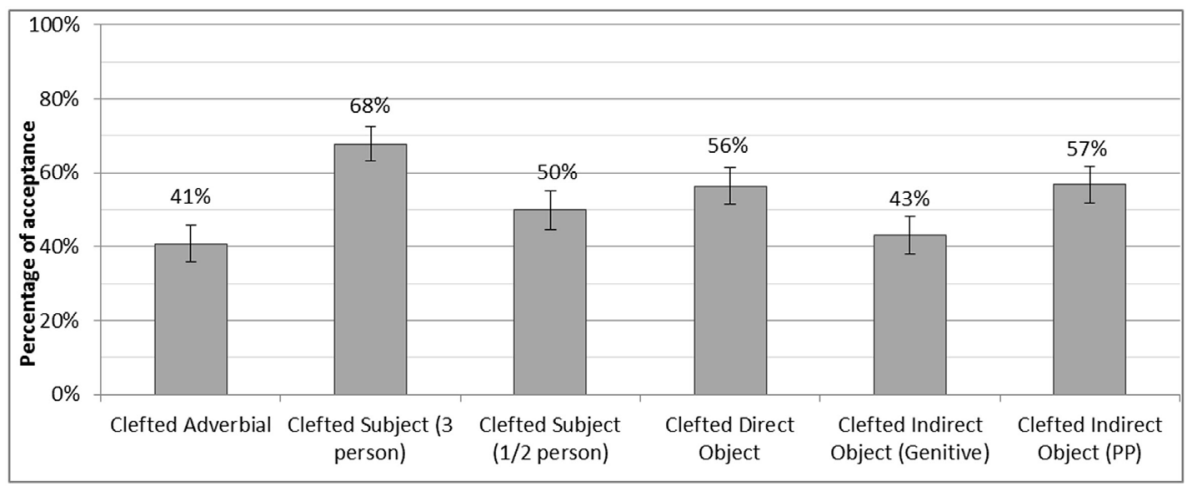

FIGURE 5 | Percentage of cleft acceptance as a function of cleft type.

A binomial test indicated that the observed acceptance rate of Clefted Subjects (first or second person) (50\%) was not significantly different from the $50 \%$ chance level, $p=1.000$ (two-sided).

A binomial test indicated that the observed acceptance rate of Clefted Direct Objects (56\%) was significantly different from the $50 \%$ chance level, $p=0.002$ (two-sided).

A binomial test indicated that the observed acceptance rate of Clefted Indirect Objects with Genitive (43\%) was not significantly different from the $50 \%$ chance level, $p=0.071$ (two-sided).

A binomial test indicated that the observed acceptance rate of Clefted Indirect Objects with PP (57\%) was not significantly different from the $50 \%$ chance level, $p=0.071$ (two-sided).

On the basis of these findings, it appears that the acceptability of focus clefts in Standard Greek, our participants' second variety, an effect which I termed "residual clefting" in the beginning of 
this article, is still quite prevalent, as is evidenced by the fact that participants performed significantly above chance. ${ }^{14}$

\section{DISCUSSION}

A closer look at the quantitative data reveals some interesting details as regards the distribution of variation in acquisition: women and the younger age group accept focus clefts in Standard Greek less than do men and the older age group, the differences between groups being statistically significant. In other words, women and younger speakers display higher rates of convergence toward the standard than do men and the older age group.

As regards variation in acquisition depending on the type of cleft, what is rather striking is the difference in acceptability between clefted first and second vs third person subjects (50 and $68 \%$, respectively). A possible explanation may be that participants accept to a lesser extent structures in which there is person mismatch between the "copula," which superficially looks like a morphological third person form, and the subject, which may in turn be taken to suggest some kind of reshuffling in the grammar, in the sense that the preference for third person clefted subjects may indicate that the "copula" is treated as having agreement features (cf. the Standard Greek data in text footnote 9).

On the whole, the imperfect acquisition of the Standard Greek focusing strategy evidenced by the data and the concomitant transfer of Cypriot Greek clefting into the target variety may at first blush appear to be puzzling. In a sense, focus raising is a "simpler" strategy than clefting, which involves a more complex biclausal structure (Grohmann et al., 2006; Tsiplakou et al., 2007). Moreover, it may be reasonably assumed that the acquisition of focus movement is not underdetermined by input, as structures with syntactic focusing are quite run-of-the-mill in the standard variety. The perseverance of clefting in standard-like production is probably less hard to account for: excluding clefting would involve focusing on negative evidence (White, 1987), i.e., somehow deducing the absence of this structure in the target variety. ${ }^{15}$ What needs to be accounted for independently is the acquisition deficit as regards the Standard Greek syntactic focusing strategy.

As stated in the introductory section, the problematic acquisition of syntactic focusing, as evidenced by the "residual clefting" data in the target variety, invites an approach in terms of the Interface Hypothesis, according to which adult second language acquisition of phenomena which only pertain to a particular module of grammar, e.g., syntax only, is ultimately fully achieved at end state, whereas acquisition of phenomena which pertain to an interface (e.g., syntax-semantics, syntax-pragmatics/syntax-discourse) is extremely hard to achieve and is almost never perfect. It is tempting to suggest that this is what underpins the imperfect acquisition of syntactic focusing in Standard Greek by Cypriot Greek speakers, as evidenced by the questionnaire data, as it would seem that an aspect of the syntax of the target variety which relates to the syntax-discourse interface has strong effects

\footnotetext{
${ }^{14}$ On optionality as non-native attainment see Sorace $(2000,2005,2006)$.

${ }^{15} \mathrm{~A}$ confounding factor may be the availability in Standard Greek of structures such as those discussed in text footnote 9 .
}

on syntactic acquisition (Montrul, 2011; Sorace, 2011; White, 2011; Tsiplakou, 2014a).

Relevant research in SLA has shown that, as regards formal grammatical properties and operations in the narrow syntax, near-native competence can be reached despite the fact that these are often underdetermined by input (Tsimpli et al., 2004; Lozano, 2006, 2008, 2016; Sorace and Filiaci, 2006; Tsimpli and Sorace, 2006; Tsimpli and Dimitrakopoulou, 2007; Tsimpli and Mastropavlou, 2007; Sorace and Serratrice, 2009). ${ }^{16}$ By contrast, syntactic focus movement involves operations not only in the narrow syntax but, crucially, at the syntax-discourse interface: in Greek syntactic focus movement involves an (interpretable) $[+\mathrm{f}]$ feature associated with an $\mathrm{F}^{0}$ in an $\mathrm{FP}$ which is lower than $\mathrm{C}$ but higher than $I$; the syntactic reflexes of $[+f]$ include changes in the word order, raising of the focused constituent to FP and concomitant I-to-F raising, which accounts for the fact that syntactically focused constituents occur in the immediately preverbal position (Tsimpli, 1995, 1998). Crucially, these operations need to be mapped on to the relevant information/discourse structures, which in turn involve notions such as old vs new, presentational vs contrastive focus (Kiss, 1998). A further complication is that in Standard Greek focused constituents in situ may be interpreted either as presentational or contrastive foci, while moved focused constituents are interpreted as contrastive foci. The acquisition of the relevant structural configurations thus involves aspects of the syntax-discourse interface and is therefore predicted to be complex, underdetermined by input, and perfect attainment is predicted to be hard to reach (Tsimpli and Sorace, 2006; Sorace, 2011). Standard Greek syntactic focus structures indeed appear to be a problematic case for acquisition, as evidenced by the persistence of transfer of focus clefts in otherwise standard(-like) production by speakers of Cypriot Greek and the level of non-native competence suggested by the data presented in this article.

\section{CONCLUSION}

In previous work it was argued that the grammatical systems of Standard and Cypriot Greek are far from converging, and this despite leveling of local subvarieties and the emergence of a

\footnotetext{
${ }^{16}$ As was mentioned earlier, exceptional clitic placement appears to present the opposite picture from that of residual clefting for bilectal grammar(s), not only in terms of full acquisition, but also as full acquisition arguably has structural effects on the syntactic system of the first variety. It is worth posing the question whether the full acquisition of Standard Greek clitic placement can be attributed to the fact that this structural phenomenon relates to formal operations in the narrow syntax, with pragmatic or discourse considerations not bearing upon the acquisition of such operations. However, Standard Greek clitic placement relates to finiteness, with proclisis depending on full person agreement on $\mathrm{T}$ (Mavrogiorgos, 2010, 2013; cf. Neokleous, 2015) or, alternatively, to verb movement to Mood or above (Agouraki, 1997, 2001; Terzi, 1999; cf. Uriagereka, 1995); in other words, in available analyses the formal operation of clitic placement also seems to involve some aspect of the syntax-semantics interface. It is worth exploring whether the differential acquisition of cliticization and syntactic focusing may be related to the fact that in the former interfacing takes place between modules of the grammar and involves formal semantic features that are arguably internal to the grammar (e.g., Mood) while in the latter interfacing also takes place between grammar and discourse, which makes for more vulnerable acquisition [as is argued, e.g. in Tsimpli and Sorace (2006), Sorace and Serratrice (2009), and Sorace (2011)].
} 
pancypriot koine which displays grammatical hybridity; in this article the suggestion was taken up that grammatical hybridity is achieved through standard-like morphological choices while the syntax of the base variety remains intact and this suggestion was explored further by examining syntactic focusing in acrolectal, standard-like production. It was shown that speakers do not achieve native-like attainment as regards Standard Greek focus movement at end state, as evidenced by the prevalence of Cypriot clefts in acrolectal, standard-like production and related acceptability judgments. An attempt was made to show that imperfect acquisition of this core area of Greek syntax may be captured by the Interface Hypothesis and the difficulties for acquisition posed by phenomena at the syntax-discourse interface. Exploring and accounting for different levels of attainment in a second, related

\section{REFERENCES}

Agouraki, Y. (1997). "On the enclisis-proclisis alternation," in Greek Linguistics '95: Proceedings of the 2nd International Conference on Greek Linguistics, eds G. Drachman, A. Malikouti-Drachman, J. Fykias, and C. Klidi (Graz: W. Neugebauer Verlag), 393-404.

Agouraki, Y. (2001). "The position of clitics in Cypriot Greek," in Proceedings of the First International Conference of Modern Greek Dialects and Linguistic Theory, eds A. Ralli, B. Joseph, and M. Janse (Patras: University of Patras), 1-18.

Arvaniti, A. (2010). Linguistic practices in Cyprus and the emergence of Cypriot Standard Greek. Mediterr. Lang. Rev. 17, 15-45.

Chatzikyriakidis, S. (2010). Clitics in 4 Dialects of Modern Greek: A Dynamic Account [Unpublished Ph.D. dissertation], King's College, University of London.

Chatzikyriakidis, S. (2012). A dynamic account of clitic positioning in Cypriot Greek. Lingua. 112, 642-672. doi:10.1016/j.lingua.2012.01.008

Condoravdi, C., and Kiparsky, P. (2002). Clitics and clause structure. J. Greek Ling. 2, 1-39. doi:10.1075/jgl.2.02con

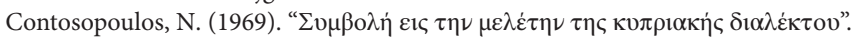

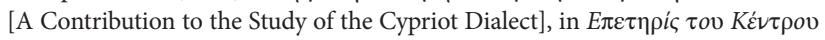

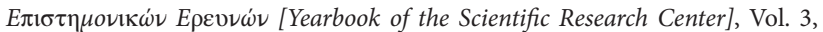
$87-109$.

Fotiou, C. (2009). "Focusing strategies in Cypriot Greek," in Selected Papers from the 2006 Cyprus Syntaxfest, eds K. K. Grohmann and P. Panagiotidis (Newcastle upon Tyne: Cambridge Scholars Publishing), 63-91.

Grohmann, K. K. (2009). "Focus on clefts: a perspective from Cypriot Greek," in Selected Papers from the 18th International Symposium on Theoretical and Applied Linguistics - Thessaloniki, ed. A. Tsangalides (Thessaloniki: Monochromia), 157-165.

Grohmann, K. K. (2011). "Some directions for the systematic investigation of the acquisition of Cypriot Greek: a new perspective on production abilities from object clitic placement," in The Development of Grammar: Language Acquisition and Diachronic Change. Volume in Honor of Jürgen M. Meisel. [Hamburg Series on Multilingualism, vol. 11.], eds E. Rinke and T. Kupisch (Amsterdam: John Benjamins), 179-203.

Grohmann, K. K., and Leivada, E. (2012). "Interface ingredients of dialect design: Bi-X, socio-syntax of development, and the grammar of Cypriot Greek," in Towards a Biolinguistic Understanding of Grammar: Essays on Interfaces. [Linguistik Aktuell/Linguistics Today], ed. A.-M. Di Sciullo (Amsterdam: John Benjamins), 239-262.

Grohmann, K. K., Panagiotidis, P., and Tsiplakou, S. (2006). "Properties of wh-question formation in Cypriot Greek," in Proceedings of the 2nd International Conference on Modern Greek Dialects and Linguistic Theory (Mytilene, Greece), eds M. Janse, B. D. Joseph, and A. Ralli (Patras: University of Patras), 83-98.

Grohmann, K. K., Papadopoulou, E., and Themistocleous, C. (2017). Acquiring clitic placement in bilectal settings: Interactions between social factors. Front. Commun. 2. doi:10.3389/fcomm.2017.00005

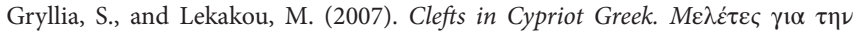

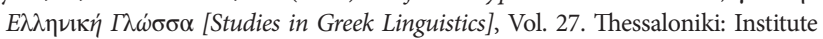
for Modern Greek Studies - Manolis Triantafyllidis Foundation, 136-148. variety along such theoretical lines in turn yields a richer understanding of gradient bilectalism.

\section{ETHICS STATEMENT}

This study was carried out in accordance with the recommendations of the "Cyprus National Bioethics Committee" with written informed consent from all subjects. All subjects gave written informed consent in accordance with the Declaration of Helsinki.

\section{AUTHOR CONTRIBUTIONS}

The author confirms being the sole contributor of this work and approved it for publication.

Hadjioannou, X., Tsiplakou, S., and Kappler, M. (2011). Language policy and language planning in Cyprus. Curr. Iss. Lang. Plan. 12, 503-569. doi:10.1080/ 14664208.2011 .629113

Horrocks, G. (1990). "Clitics in Greek. A diachronic review," in Greek Outside Greece II, eds M. Roussou and S. Panteli (Athens: Diaspora Books), 35-52.

Kanikli, A. (2011). The Syntax of wh-Questions in Cypriot Greek and Its Consequences [Unpublished PhD Dissertation], University of York.

Kerswill, P. (2010). "Sociolinguistic approaches to language change: phonology," in The SAGE Handbook of Sociolinguistics, eds R. Wodak, B. Johnstone, and P. Kerswill (SAGE Publications), 219-235.

Kiss, K. É (1998). Identificational focus versus information focus. Language 74, 245-273. doi:10.1353/lan.1998.0211

Kroch, A. (1994). "Morphosyntactic variation," in Papers from the 30th Regional Meeting of the Chicago Linguistics Society: Parasession on Variation and Linguistic Theory, eds K. Beals, R. Denton, R. Knippen, L. Melnar, H. Suzuki, and E. Zeinfeld (Chicago: Chicago Linguistics Society), 180-201.

Kroch, A., and Taylor, A. (2000). "Verb-object order in Middle English," in Diachronic Syntax: Models and Mechanisms, eds S. Pintzuk, G. Tsoulas, and A. Warner (Oxford: Oxford University Press), 132-163.

Leivada, E., Papadopoulou, E., and Pavlou, N. (2017). Grammatical hybridity in a non-standard variety and its implications for Universal Grammar. A spontaneous speech corpus study. Front. Psychol. 8:1260. doi:10.3389/fpsyg. 2017.01260

Lozano, C. (2006). Focus and split intransitivity: the acquisition of word order alternations and unaccusativity in L2 Spanish. Sec. Lang. Res. 22, 145-187. doi:10.1191/0267658306sr264oa

Lozano, C. (2008). The Acquisition of Syntax and Discourse: Pronominals and Word Order in English and Greek Learners of Spanish. Saarbrücken: VDM Verlag.

Lozano, C. (2016). "Pragmatic principles in anaphora resolution at the syntaxdiscourse interface: advanced English learners of Spanish in the CEDEL2 corpus," in Spanish Learner Corpus Research: Current Trends and Future Perspectives, ed. M. Alonso Ramos (Amsterdam: John Benjamins), 236-265.

Mavrogiorgos, M. (2010). Clitics in Greek: A Minimalist Account of Proclisis and Enclisis. Amsterdam: John Benjamins.

Mavrogiorgos, M. (2013). "Enclisis at the syntax-PF interface," in Challenging Clitics [Linguistik Aktuell/Linguistics Today 206], eds C. Meklenborg Salvesen and H. P. Helland (Amsterdam: John Benjamins), 27-54.

Melissaropoulou, D., Themistocleous, C., Tsiplakou, S., and Tsolakidis, S. (2013). "The present perfect in Cypriot Greek revisited," in Studies in Language Variation - European Perspectives IV. Selected Papers from the $6^{\text {th }}$ International Conference on Language Variation in Europe (ICLaVE 6), eds P. Auer, J. Caro Reina, and G. Kaufmann (Amsterdam: John Benjamins), 159-172.

Merchant, J., and Pavlou, N. (2017). The morphosyntax of the periphrastic future under negation in Cypriot Greek. J. Greek Linguist. 17, 233-262. doi:10.1163/15699846-01702005

Montrul, S. (2011). Multiple interfaces and incomplete acquisition. Lingua. 121, 591-604. doi:10.1016/j.lingua.2010.05.006

Neokleous, T. (2015). The L1 acquisition of clitic placement in Cypriot Greek. Lingua. 161, 27-47. doi:10.1016/j.lingua.2015.04.003 
Papadopoulou, E., Leivada, E., and Pavlou, N. (2014). Acceptability judgments in bilectal populations. Competition, gradience and socio-syntax. Linguist. Var. 14, 109-128. doi:10.1075/lv.14.1.05pap

Papapavlou, A. (1998). Attitudes toward the Greek Cypriot dialect: Sociocultural implications. Int. J. Soc. Lang. 18, 15-28.

Pappas, P. A. (2004). Variation and Morphosyntactic Change in Greek: From Clitics to Affixes. New York: Palgrave Macmillan.

Pappas, P. A. (2014). Exceptional clitic placement in Cypriot Greek: results from an MET Study. J. Greek Ling. 14, 190-211. doi:10.1163/15699846-01402002

Revithiadou, A. (2006). Prosodic filters on syntax: an interface account of second position clitics. Lingua. 116, 79-111. doi:10.1016/j.lingua.2004.08.017

Revithiadou, A. (2008). A cross-dialectal study of cliticization in Greek. Lingua. 118, 1393-1415. doi:10.1016/j.lingua.2007.05.008

Rowe, C., and Grohmann, K. K. (2013). Discrete bilectalism: towards co-overt prestige and diglossic shift in Cyprus. Int. J. Soc. Lang. 224, 119-142. doi:10.1515/ ijsl-2013-0058

Sorace, A. (2000). Syntactic optionality in non-native grammars. Sec. Lang. Res. 16, 93-102. doi:10.1191/026765800670666032

Sorace, A. (2005). "Syntactic optionality at interfaces," in Syntax and Variation: Reconciling the Biological and the Social, eds L. Cornips and K. Corrigan (Amsterdam: John Benjamins), 46-111.

Sorace, A. (2006). "Gradience and optionality in mature and developing grammars," in Gradience in Grammars: Generative Perspectives, eds G. Fanselow, C. Fery, M. Schlesewsky, and R. Vogel (Oxford: Oxford University Press), 106-123.

Sorace, A. (2011). Pinning down the concept of "interface" in bilingualism. Linguist. Approach. Biling. 1, 1-33. doi:10.1075/lab.1.1.01sor

Sorace, A., and Filiaci, F. (2006). Anaphora resolution in near-native speakers of Italian. Sec. Lang. Res. 22, 339-368. doi:10.1191/0267658306sr271oa

Sorace, A., and Serratrice, L. (2009). Internal and external interfaces in bilingual language development: beyond structural overlap. Int. J. Biling. 13, 195-210. doi:10.1177/1367006909339810

Terkourafi, M. (2005). Understanding the present through the past. Processes of koineisation in Cyprus. Diachronica 22, 309-372. doi:10.1075/dia.22.2.04ter

Terzi, A. (1999). Clitic combinations, their hosts and their ordering. Nat. Lang. Ling. Theory 17, 85-121. doi:10.1023/A:1006075626603

Trudgill, P. (1999). New-dialect formation and dedialectalization: embryonic and vestigial variants. J. Eng. Ling. 27, 319-327. doi:10.1177/00754249922004741

Tsimpli, I., and Sorace, A. (2006). "Differentiating interfaces: L2 performance in syntax-semantics and syntax-discourse phenomena," in Proceedings of the 30th Annual Boston University Conference on Language Development (Somerville, MA: Cascadilla Press), 653-664

Tsimpli, I. M. (1995). "Focusing in Modern Greek," in Discourse Configurational Languages. [Oxford Studies in Comparative Syntax], ed. K. É Kiss (Oxford: Oxford University Press), 176-206.

Tsimpli, I. M. (1998). "Individual and functional readings for focus, wh- and negative operators: Evidence from Greek," in Themes in Greek Linguistics II, eds B. D. Joseph, G. C. Horrocks, and I. Philippaki-Warburton (Amsterdam: John Benjamins), 197-228.

Tsimpli, I. M., and Dimitrakopoulou, M. (2007). The interpretability hypothesis: evidence from wh-interrogatives in second language acquisition. Sec. Lang. Res. 23, 215-242. doi:10.1177/0267658307076546

Tsimpli, I. M., and Mastropavlou, M. (2007). "Feature interpretability in L2 acquisition and SLI: Greek Clitics and Determiners," in The Role of Formal Features in Second Language Acquisition, eds H. Goodluck, J. Liceras, and H. Zobl (London/New York: Routledge), 143-183.

Tsimpli, I. M., Sorace, A., Heycock, C., and Filiaci, F. (2004). First language attrition and syntactic subjects: a study of Greek and Italian near-native speakers of English. Int. J. Biling. 8, 257-277. doi:10.1177/13670069040080030601
Tsiplakou, S. (2006). "Cyprus: language situation," in Encyclopedia of Language and Linguistics, 2nd Edn, ed. K. Brown (Oxford: Elsevier), 337-339.

Tsiplakou, S. (2009a). Code-switching and code mixing between related varieties: establishing the blueprint. Int. J. Human. 6, 49-66. doi:10.18848/1447-9508/ cgp/v06i12/42576

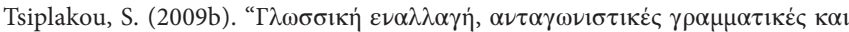

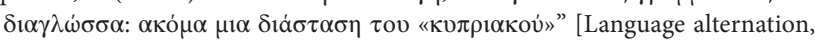
competing grammars and interlanguage: another facet of the "Cyprus problem"], in Proceedings of the 8th International Conference on Greek Linguistics (Ioannina, 30/8-2/9/2007), eds G. K. Giannakis, M. Baltazani, G. J. Xydopoulos, and A. Tsangalidis (Ioannina: University of Ioannina), 1195-1209.

Tsiplakou, S. (2011). "Linguistic attitudes and emerging hyperdialectism in a diglossic setting: young Cypriot Greeks on their language," in Berkeley Linguistic Society 29. Special Volume: Minority and Diasporic Languages of Europe, ed. C. Yoquelet (Berkeley, CA: University of California at Berkeley), 120-132.

Tsiplakou, S. (2014a). How 'mixed' is a mixed system? The case of the Cypriot Greek koine. Ling. Var. 14, 161-178. doi:10.1075/lv.14.1.07tsi

Tsiplakou, S. (2014b). "Does convergence generate stability? The case of the Cypriot Greek koiné," in Stability and Divergence in Language Contact. Factors and Mechanisms, eds K. Braunmüller, S. Höder, and K. Kühl (Amsterdam/ Philadelphia: John Benjamins), 165-177.

Tsiplakou, S., Armosti, S., and Evripidou, D. (2016). Coherence 'in the mix'? Coherence in the face of language shift in Cypriot Greek. Lingua. 17, 10-25. doi:10.1016/j.lingua.2015.10.014

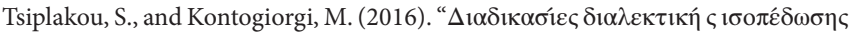

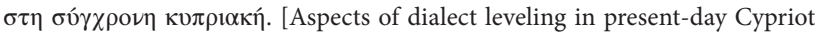

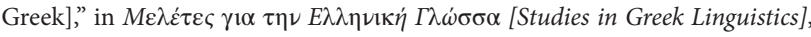
Vol. 36 (Thessaloniki: Institute for Modern Greek Studies - Manolis Triantafyllidis Foundation), 451-464.

Tsiplakou, S., Panagiotidis, P., and Grohmann, K. K. (2007). "Properties of Cypriot Greek wh-question formation," in Proceedings of the 7th International Conference on Greek Linguistics, eds G. Tsoulas and A. Galani (York: University of York). Available at: http://icgl7.icte.uowm.gr

Tsiplakou, S., Papapavlou, A., Pavlou, P., and Katsoyannou, M. (2006). "Levelling, koineization and their implications for bidialectism," in Language Variation European Perspectives. Selected Papers from the 3rd International Conference on Language Variation in Europe (ICLaVE 3), Amsterdam, ed. F. Hinskens (John Benjamins), 265-276.

Uriagereka, J. (1995). Aspects of the syntax of clitic placement in Western Romance. Linguist. Inq. 26, 79-123.

White, L. (1987). Against comprehensible input: the input hypothesis and the development of second-language competence. Appl. Ling. 8, 95-110. doi:10.1093/applin/8.2.95

White, L. (2011). Second language acquisition at the interfaces. Lingua. 121, 577-590. doi:10.1016/j.lingua.2010.05.005

Conflict of Interest Statement: The author declares that the research was conducted in the absence of any commercial or financial relationships that could be construed as a potential conflict of interest.

Copyright $\odot 2017$ Tsiplakou. This is an open-access article distributed under the terms of the Creative Commons Attribution License (CC BY). The use, distribution or reproduction in other forums is permitted, provided the original author(s) or licensor are credited and that the original publication in this journal is cited, in accordance with accepted academic practice. No use, distribution or reproduction is permitted which does not comply with these terms. 